\title{
Comparisons of Antioxidant Status in Different Sport Type Athletes 不同運動形式運動員之抗氧化狀態比較
}

\author{
Ying-Chih $\mathrm{HO}^{1}$ Shu-Ling $\mathrm{LI}^{2}$ \\ Fu-An CHEN $^{3}$ Mei-Chich HSU
}

${ }^{1}$ Physical Education Center, Nan-Hua University, TAIWAN

2 Institute of Physical Education,

National Taiwan College of Physical Education, TAIWAN

${ }^{3}$ Department of Pharmacy and

Graduate Institute of Pharmaceutical Technology, TAIWAN

${ }^{4}$ Institute of Sports Science,

National College of Physical Education and Sports, TAIWAN

\section{何應志 ${ }^{1} \quad$ 李淑玲 ${ }^{2}$ 陳福安 ${ }^{3}$ 許美智 $^{4}$ \\ 台灣南華大學體育中心 \\ ²台灣國立體育學院體育研究所 \\ ${ }^{3}$ 台灣大仁科技大學藥學系 \\ ${ }^{4}$ 台灣國立體育學院運動科學研究所}

\begin{abstract}
This study investigated the resting levels of malondialdehyde plus 4-hydroxy 2-(E)-nonenal (MDA+4-HNE) in plasma, erythrocyte superoxide dimutase (SOD) and glutathione (GSH) in 12 long-distance runners (LR), 12 weight lifters (WL), and 12 age match sedentary nonathletes (SN). The subjects were asked to maintain the lifestyle and original training (Monday to Friday) and were requested not to take any medicines and supplementation two weeks ago before sampling. No significant differences were found in MDA+4-HNE levels among three groups. The LR group had lower erythrocyte SOD activities than SN group ( $\mathrm{p}<0.05)$. Additionally, the erythrocyte GSH concentrations in WL group was significantly lower than LR and SN groups $(\mathrm{p}<0.05)$. The results indicated that the adaptation and changes in resting antioxidant status would be different due to various exercise training modes. Furthermore, athletes should take the antioxidant supplementation appropriately to overcome the high oxidative stress cause by heavy training.
\end{abstract}

Key words: antioxidant, SOD, GSH, training.

\section{摘 要}

本實驗比較經長期運動訓練之12位舉重選手、12位長跑選手, 以及12未受訓練的坐式生活者, 其休息狀態下血液中抗氧化數 值之差異。抗氧化數據包括血漿中之MDA+4HNE, 紅血球中之過氧化物歧化酶(superoxide dismutase; SOD)之活性及穀胱甘肽 (glutathione; GSH)之含量。受試者維持其原本之生活型態及訓練(星期一至星期五), 從兩個星期前即不能服用藥物及營養補充劑。 結果顯示三組間血漿中脂質過氧化產物MDA $+4 \mathrm{HNE之}$ 濃度並無明顯差異, 長跑選手紅血球SOD之活性明顯較坐式生活者來得低 $(\mathrm{p}<.05)$, 舉重選手紅血球GSH含量明顯較其他兩組來得低 $(\mathrm{p}<.05)$ 。結果顯示, 不同的訓練可能會造成不同型式的氧化壓力, 經過 長期之適應後, 體內的抗氧化狀態也有所差異。此外, 為了抵抗高度訓練所造成之氧化壓力, 運動員應該適當的補充抗氧化劑。

關鍵詞：抗氧化劑，過氧化物歧化酶，穀胱甘肽，運動訓練 


\section{Introduction}

Strenuous physical activity and heavy training are known to increase the production of reactive oxygen species (ROS). When ROS produce, it will lead to lipid peroxidation. Lipid peroxidation generally associated with antioxidant defence. In the beginning, most of the evidence has implicated that aerobic exercise is the major source of oxidative stress, but it is becoming increasingly clear that acute bouts of anaerobic exercise can also lead to an oxidative stress.

An acute bout of exercise is known to increase the activities of antioxidant enzymes, including superoxide dismutase(SOD), catalase, and GSH peroxidase(GPX) in skeletal muscle, heart and liver (Chakraborti, et al., 1998). On the other hand, studies have shown the depletion of antioxidants occur immediately after exercise and supplementation of antioxidants in the diet have a protective effect on exercise-induce oxidative stress (Rokitzki, et al., 1994). Even though acute physical exercise will increase oxidative stress, several studies have shown that regular training program including aerobic and anaerobic can improve antioxidant status (Oztasan, et al., 2004; Parise, et al., 2005).

After long-term heavy sports training and adaptation, the antioxidant status in athletes would be different from sedentary individuals. According to the past study, erythrocyte SOD activity was higher in the footballer (Metin, et al., 2003). However, study also reported that athletes have lower vitamin $\mathrm{C}$ and GSH plasma concentrations and higher resting lipoperoxidation status (Balakrishnan \& Anuradha, 1998).

Since it has been suggested that oxidative stress is specific to anaerobic exercise (e.g., isometric, eccentric, resistance, and sprint training) and may be mediated through various pathways from aerobic exercise, the adaptation in antioxidant status might be discrepancy due to varied exercise training modes. Therefore, the purpose of the study was to investigate the resting antioxidant status between long-distance runners (aerobic training), weight lifters (anaerobic training) and sedentary group.

\section{Methods}

\section{Subjects}

Twelve competitive weight lifters and long-distance runners from the National College of Physical Education and Sports (Taoyuan, Taiwan), and 12 healthy age matched sedentary subjects were recruited. The study conformed to the ethical guidelines of the National College of Physical Education and Sports (Taoyuan, Taiwan) and was approved by the Human Research Ethics Committee. All volunteers provided written consent for participation in this study. In a pre-study interview, information on routine use of vitamins and other nutritional supplements was obtained for each participant. Volunteers who were found to take any regular medication were not included in the study.

\section{Study Design}

The study was practiced during the winter training period (January and February). The athletes were training from Monday to Friday and were asked to take a fullrest on Saturday and Sunday. At the last week of the training period, blood samples were collected. In the morning of the sampling day, the fasted subjects (for 8 hr prior to the test) arrived at the laboratory at eight. After $20 \mathrm{~min}$ of seated rest, a catheter was placed in an antecubital vein, and blood samples of each subject were collected.

\section{Sample Collection and Analysis}

Twenty milliliters of venous blood were collected from each subject. Blood samples were immediately transferred to chilled EDTA glass tubes. Portions of whole-blood samples were separated for superoxide dimutase (SOD) and glutathione (GSH) measurements. Erythrocyte fractions were resuspended to the original blood volume and washed with a cold isotonic saline solution. Erythrocytes were stored at $-30{ }^{\circ} \mathrm{C}$ until analysis. The remaining blood samples were centrifuged for $15 \mathrm{~min}$ at $2500 \times \mathrm{g}, 4^{\circ} \mathrm{C}$, and the resulting plasma were stored at $-30^{\circ} \mathrm{C}$ until assay of malondialdehyde and 4-hydroxy 2(E)-nonenal (MDA+4-HNE).

To evaluate blood antioxidant status, erythrocyte SOD activity and GSH contents were determined using commercial kits (Calbiochem Co., USA), and were expressed as units per gram of hemoglobin and millimoles per liter, respectively. As an index of plasma liquid 
peroxidation, plasma MDA and 4-HNE concentrations were also determined directly using a commercial kit (Calbiochem Co., USA), and then analyzed by a spectrophotometer (Shimadzu, UV-1201).

\section{Statistical Analysis}

Data from each group are expressed as mean \pm standard deviation (SD). The means of one-way analysis of variance test followed by Tukey's post hoc test was used to determine the significant differences between each group. Differences were considered significant when $p<0.05$.

\section{Results}

Age, height, weight, and body fat were shown in Table1. Resting oxidant and antioxidant status of three groups were presented in Table 2. No significant differences were found in MDA+4-HNE levels among three groups. The LR group had lower erythrocyte SOD activities than $\mathrm{SN}$ group $(\mathrm{p}<0.05)$. And the erythrocyte GSH contents in WL group were significantly lower than LR and SN groups $(\mathrm{p}<0.05)$.

\section{Discussion}

In this study, we compared the resting antioxidants status including liquid peroxidation (MDA+4-HNE), antioxidant enzyme (SOD) activity and antioxidant substance (GSH) in long-distance runners, weight lifters, and sedentary group. Although there were no significant differences in plasma MDA+4-HNE level among three groups, we found that the erythrocyte SOD activity in LR group were lower and the erythrocyte GSH contents in WL group were lower too.

Mammalian tissues contain enzymatic and nonenzymatic antioxidant defense systems that protect against or minimize oxidative tissue damage caused by ROS. Because most of the ROS are thought to be generated as $\mathrm{O}_{2}{ }^{--}$in vivo, superoxide dismutase (SOD), which is a scavenger of $\mathrm{O}_{2}{ }^{-}$, is one of the most important enzymes in the antioxidant defense system. Mammals have three kinds of SOD isoenzymes: CuZn-SOD (SOD1) which is localized predominantly in the cytosol; Mn-SOD (SOD2) which is present mostly in the mitochondrial matrix; and extracellular SOD (EC-SOD, SOD3) which is localized in extracellular fluid, such as plasma, and in the extracellular matrix of tissues. So the erythrocyte SOD we detected in this study is mainly CuZn-SOD.

In contrast to the lower erythrocyte SOD activity in LR group in our study, Marzatico et al. (1997) found the higher erythrocyte SOD activity in marathon runners compared with control subjects, and Metin et al. (2003) also found the higher erythrocyte SOD activity in young male footballers. According to the past studies of investigating the effects of endurance training on SOD, most studies indicated that CuZn-SOD were upregulated by endurance training, only Oztasan et al. (2004) reported the erythrocyte SOD was decreased in trained rats at rest compared to the sedentary group. And they explained the discrepancies in the erythrocyte SOD activity among studies may result from different modes of training, different intensity of training and different species. Besides, Ookawara et al. (2003) also found the endurance training decreased the plasma EC-SOD level at rest by $22.2 \%$ but they indicated that EC-SOD levels were changed in a different manner from the CuZn-SOD and Mn-SOD, and plasma EC-SOD assay may serve as a new index of endurance training.

Since the CuZn-SOD was consisted of copper and zinc, these trace metals must be a decisive role in erythrocyte SOD activity. In a study by Reeves et al. (2004) male rats, fed a diet with and without zinc, copper or manganese, showed symptoms with their copperdeficient diet, there was decreased activity in red blood cell CuZn-SOD. Tungtrongchitr et al. (2003) also indicated that low SOD activity found in the overweight and obese subjects might be caused by low zinc intake. In our studies, training athletes, as compared to nontraining control subjects, indicate the increasing potential loss of minerals in sweat and urine (Lukaski, 1995). In addition, study reported that the mean urinary concentration of $\mathrm{Zn}$ and $\mathrm{Cu}$ increased significantly after cessation of physical exercise (kikukawa \& kobayashi, 2002). Furthermore, Resina et al. (1990) reported male trained runners had the lower serum copper concentrations compared to the control group. Therefore, the deficiency of copper and zinc in LR group might be the reason caused by the lower erythrocyte SOD activity.

In our study, following long-term resistance training, the erythrocyte SOD activity in WL group did not show significantly difference from $\mathrm{SN}$ group. To date, there have been no reports documenting the changes in 
antioxidant enzymes following either acute or chronic resistance exercise. This is surprisingly given the fact that resistance exercise is known to induce an inflammatory response (Stupka, et al., 2000; Beaton, et al., 2002). In addition, ROS generated by the enzyme xanthine oxidase, may further contribute to cytosolic oxidative stress in response to an increased calcium load (Kondo, et al., 1993). Parise et al. (2005) also demonstrate that 14 weeks of resistance exercise training had no effect on the protein content of catalase, CuZn-SOD, or Mn-SOD.

Unlike the erythrocyte SOD activity, the erythrocyte GSH contents in WL group had dramatic changes. Different from the long-distance runners, the training programs of weight lifters involve a lot of resistance exercise training. Repeated bouts of ischemia and reperfusion in muscle during exercise can lead to the formation of free radicals such as superoxide via activation of the xanthine-xanthine oxidase pathway (Sussman \& Bulkley 1990). As muscular contractions at or above $40 \%$ of maximal voluntary contraction, it can produce transient ischemia in the muscle (Donald, et al. 1967). Elevations in both plasma and tissue levels of xanthine oxidase (Hellsten, et al., 1997; Vina, et al., 2000) and hypoxanthine (Ihara, et al., 2001) have been reported in several studies after either isometric or dynamic exhaustive anaerobic exercise. Such elevations in xanthine oxidase have been associated with a rise in lipid peroxidation resulting from anaerobic exercise (Radak, et al., 1996). Further evidence for the role of xanthine oxidase in mediating increased RONS was presented by Vina and colleagues (2000), who reported that inhibition of xanthine oxidase with allopurinol prevented exercise-induced oxidation of GSH in both humans and rats.

GSH play a multifunctional role in protecting tissues from oxidative damage during exercise, almost all of the blood glutathione represents blood cell content, mainly that of the erythrocyte (Sen, 1999). Exercising skeletal muscle seems to import GSH from the plasma during exercise (Ji, 1995). Because little de novo GSH synthesis occurs in skeletal or cardiac muscle, it seems that muscle are capable of adapting to chronic oxidative stress by an increased uptake of extramuscular GSH. It is well known, weight lifters were usually strong and muscular, so the exercising skeletal muscle might uptake more GSH from blood, in the other way, more muscle generate more xanthine oxidase into blood and induce the oxidation of erythrocyte GSH, and these effects might be the mechanisms that decreased the erythrocyte GSH contents in WL group.

MDA+4-HNE level is usually as a quantitative marker for free radical interaction with cell membrane. We didn't find the discrepancy in plasma MDA+4-HNE level between sportsmen and sedentary group. In agreement with our finding, most studies that using untrained subjects and following design training program have show training did not alter liquid peroxidation level at rest (Senturk, et al., 2001; Oztasan, et al., 2004). But in sportsmen studies, increased plasma MDA and conjugated diene level were found in marathon runners at rest (Marzatico, et al., 1997), and Mena et al. (1991) also found plasma MDA level were markedly increased in professional cyclists at rest. In contrast, Metin et al. (2003) found the lower plasma MDA level in footballers at rest. Because we collected the blood sample on Monday morning, after the full-rest on Saturday and Sunday, the oxidative stress induced by training seems to be slight.

Since the oxidative stress of aerobic and anaerobic exercise were mediated through the various pathways, this study indicated that the adaptation in antioxidant status were discrepancy due to varied exercise training modes. We found the LR group had lower erythrocyte SOD activities, and this might cause the deficiency of copper and zinc. So it is important to monitored the plasma trace metals and supplement appropriately in LR. We also found the lower erythrocyte GSH contents in WL group. Indeed, several compounds have been used widely in protecting ischemia-reperfusion caused by myocardial oxidative damage. $\mathrm{N}$-acetylcysteine (NAC), free GSH, and GSH acetyl monoester are considered the chosen compounds of supplementation ( $\mathrm{Ji}, 1995)$. In summary, in order to overcome the high oxidative stress cause by heavy training, athletes should monitor the antioxidant status by analyzing the oxidants and antioxidant markers in blood regularly, and supplement the antioxidant substance appropriately. 
Table 1. Subjects Characteristics.

\begin{tabular}{llll}
\hline Parameter & WL & LR & SN \\
\hline Age(years) & $20.8 \pm 1.1$ & $20.5 \pm 1.7$ & $20.1 \pm 0.9$ \\
Height $(\mathrm{cm})$ & $168.5 \pm 4.4$ & $173.3 \pm 3.9$ & $172.6 \pm 4.9$ \\
Weight $(\mathrm{kg})$ & $87.3 \pm 19.4$ & $61.4 \pm 5.8$ & $67.1 \pm 11.1$ \\
Body fat $(\%)$ & $22.8 \pm 7.0$ & $11.3 \pm 3.1$ & $17.9 \pm 3.8$
\end{tabular}

Values are mean \pm SD

WL, weight lifters; LR, long-distance runners; SN, sedentary nonathletes.

* $\mathrm{p}<0.05$ relative to $\mathrm{SN}$

\# $\mathrm{p}<0.05$ relative to $\mathrm{LR}$

Table 2. Levels of Resting Antioxidant Parameters in Three Groups.

\begin{tabular}{llll}
\hline Parameter & WL & LR & SN \\
\hline SOD(U/mg Hb) & $0.68 \pm 0.24$ & $0.42 \pm 0.24 *$ & $0.92 \pm 0.33$ \\
GSH(mmol/L) & $399 \pm 172 *^{*}$ & $676 \pm 181$ & $727 \pm 189$
\end{tabular}

$\mathrm{MDA}+4-\mathrm{HNE}(u \mathrm{~mol} / \mathrm{L}) \quad 4.03 \pm 0.63 \quad 4.79 \pm 1.19 \quad 4.45 \pm 1.40$

Values are mean \pm SD.

WL, weight lifters; LR, long-distance runners; SN, sedentary nonathletes.

* $\mathrm{p}<0.05$ relative to $\mathrm{SN}$

\# $\mathrm{p}<0.05$ relative to $\mathrm{LR}$

\section{Reference}

Balakrishnan, S.D., \& Anuradha, C.V. (1998). Exercise, depletion of antioxidants and antioxidant manipulation. Cell Biochemistry \& Function, 16, 269-275.

Beaton, L.J., Allan, D.A., Tarnopolsky, M.A., Tiidus, P.M., \& Phillips, S.M. (2002). Contraction-induced muscle damage is unaffected by vitamin E supplementation. Medicine and Science in Sports and Exercise, 34(5), 798-805.

Chakraborti, T., Ghosh, S.K., Michael, J.R., Batabyal, S.K., \& Chakraborti, S. (1998). Targets of oxidative stress in cardiovascular system. Molecular and Cellular Biochemistry, 187(1-2), 1-10.
Donald, K.W., Lind, A.R., \& McNichol, G.W. (1967). Cardiovascular responses to sustained (static) contractions. Circulation Research, 20, 15-32.

Hellsten, Y., Frandsen, U., Orthenblad, N., Sjodin, B., \& Richter, E.A. (1997). Xanthine oxidase in human skeletal muscle following eccentric exercise: a role in inflammation. The Journal of Physiology, 498, 239248.

Ihara, H., Shino, Y., Morita, Y., Kawaguchi, E., Hashizume, N., \& Yoshida, M. (2001). Is skeletal muscle damaged by the oxidative stress following anaerobic exercise? Journal of Clinical Laboratory Analysis, 15(5), 239243.

Ji, L.L. (1995). Oxidative stress during exercise: implication of antioxidant nutrients. Free Radical Biology and Medicine, 18(6), 1079-1086.

Kikukawa, A., \& Kobayashi, A. (2002). Changes in urinary zinc and copper with strenuous physical exercise. Aviation Space and Environmental Medicine, 73(10), 991-995.

Kondo, H., Nakagaki, I., Sasaki, S., Hori, S., \& Itokawa, Y. (1993). Mechanism of oxidative stress in skeletal muscle atrophied by immobilization. American Journal of Physiology, 265, E839-844.

Lukaski, H.C. (1995). Micronutrients (magnesium, zinc, and copper): are mineral supplements needed for athletes? International Journal of Sport Nutrition, 5 Suppl, S74-S83.

Marzatico, F., Pansarasa, O., Bertorelli, L., Somenzini, L., \& Della Valle, G. (1997). Blood free radical antioxidant enzymes and lipid peroxides following long-distance and lactacidemic performances in highly trained aerobic and sprint athletes. Journal of Sports Medicine and Physical Fitness, 37(4), 235-239.

Mena, P., Maynar, M., Gutierrez, J. M., Maynar, J., Timon, J., \& Campillo, J. E. (1991). Erythrocyte free radical scavenger enzymes in bicycle professional racers adaptation to training. International Journal of Sports Medicine, 12(6), 563-566. 
Metin, G., Atukeren, P., Alturfan, A. A., Gulyasar, T., Kaya, M., \& Gumustas, K. (2003). Lipid peroxidation, erythrocyte superoxide-dismutase activity and trace metals in young male footballers. Yonse $i$ Medical Journal, 44(6), 979-986.

Ookawara, T., Haga, S., Ha, S., Oh-Ishi, S., Toshinai, K., Kizaki, T., Ji, L.L., Suzuki, K., \& Ohno, H. (2003). Effects of endurance training on three superoxide dismutase isoenzymes in human plasma. Free Radical Research, 37(7), 713-719.

Oztasan, N., Taysi, S., Gumustekin, K., Altinkaynak, K., Aktas, O., Timur, H., Siktar, E., Keles, S., Akar, S., Akcay, F., Dane, S., \& Gul, M. (2004). Endurance training attenuates exercise-induced oxidative stress in erythrocytes in rat. European Journal of Applied Physiology, 91(5-6), 622-627.

Parise, G., Brose, A.N., \& Tarnopolsky, M.A. (2005). Resistance exercise training decreases oxidative damage to DNA and increases cytochrome oxidase activity in older adults. Experimental Gerontology, 40(3), 173-180.

Radak, Z., Asano, K., Inoue, M., Kizaki, T., Oh-Ishi, S., Suzuki, K., Taniguchi, N., \& Ohno, H. (1996). Superoxide dismutase derivative prevents oxidative damage in liver and kidney of rats induced by exhausting exercise. European Journal of Applied Physiology and Occupational Physiology, 72(3), 189194.

Reeves, P.G., Ralston, N.V., Idso, J.P., \& Lukaski, H.C. (2004). Contrasting and cooperative effects of copper and iron deficiencies in male rats fed different concentrations of manganese and different sources of sulfur amino acids in an AIN-93G-based diet. The Journal of Nutrition, 134(2), 416-425.

Resina, A., Fedi, S., Gatteschi, L., Rubenni, M.G., Giamberardino, M.A., Trabassi, E., \& Imreh, F. (1990). Comparison of some serum copper parameters in trained runners and control subjects. International Journal of Sports Medicine, 11(1), 58-60.

Rokitzki, L., Logemann, E., Sagredos, A.N., Murphy, M., Wetzel-Roth, W., \& Keul, J. (1994). Lipid peroxidation and antioxidative vitamins under extreme endurance stress. Acta Physiologica Scandinavica, 151(2),149-158.
Sen, C.K. (1999). Glutathione homeostasis in response to exercise training and nutritional supplements. Molecular and Cellular Biochemistry, 196(1-2), 31-42.

Senturk, U.K., Gunduz, F., Kuru, O., Aktekin, M.R., Kipmen, D., Yalcin, O., Bor-Kucukatay, M., Yesilkaya, A., \& Baskurt, O.K. (2001). Exerciseinduced oxidative stress affects erythrocytes in sedentary rats but not exercise-trained rats. Journal of Applied Physiology, 91(5), 1999-2004.

Stupka, N., Lowther, S., Chorneyko, K., Bourgeois, J.M., Hogben, C., \& Tarnopolsky, M.A. (2000). Gender differences in muscle inflammation after eccentric exercise. Journal of Applied Physiology, 89(6), 23252332.

Sussman, M.S., \& Bulkley, G.B. (1990). Oxygen-derived free radicals in reperfusion injury. Methods in Enzymology, 186, 711-723.

Tungtrongchitr, R., Pongpaew, P., Phonrat, B., Tungtrongchitr, A., Viroonudomphol, D., Vudhivai, N., \& Schelp, F.P. (2003). Serum copper, zinc, ceruloplasmin and superoxide dismutase in Thai overweight and obese. Journal of the Medical Association of Thailand, 86(6), 543-551.

Vina, J., Gimeno, A., Sastre, J., Desco, C., Asensi, M., Pallardo, F.V., Cuesta, A., Ferrero, J. A., Terada, L.S., \& Repine, J.E. (2000). Mechanism of rree radical production in exhaustive exercise in humans and rats; Role of xanthine oxidase and protection by allopurinol. IUBMB Life 49: 539-544.

\section{Correspondence}

Dr. Mei-Chich Hsu

Graduate Institute of Sports Science, National College of Physical Education \& Sports. Taoyuan County, Taiwan, R.O.C.

250, Wenhua 1st Rd, Gueishan, Taoyuan,

Taiwan 333, R.O.C

E-mail: meichich1224@mail2000.com.tw

Telephone: 886-3-3283201 ext. 2604 or 2619

Fax: 886-3-3311843 